\title{
Correction to: Regional prescription surveillance of phosphate binders in the western Saitama area: the substantial role of ferric citrate hydrate in improving serum phosphorus levels and erythropoiesis
}

\author{
Hiroaki Amano ${ }^{1} \cdot$ Yoichi Ohno $^{1,2} \cdot$ Tsutomu Inoue $^{1} \cdot$ Koji Tomori $^{1} \cdot$ Kazuya Ohama $^{3} \cdot$ Hirokazu Okada $^{1}$
}

Published online: 25 September 2019

(c) Japanese Society of Nephrology 2019

\section{Correction to: \\ Clinical and Experimental Nephrology \\ (2019) 23:841-851 \\ https://doi.org/10.1007/s10157-019-01715-8}

In the Original publication, Under the Table 1, the number of participants in the April has been incorrectly published as 1373 . The corrected table is given below:

Table 1 Patient characteristics

\begin{tabular}{|c|c|c|c|}
\hline Characteristics & April & September & $p$ value \\
\hline Participants & 1374 & & \\
\hline Sex (male \%) & 63 & & \\
\hline Age & 68 [60-76] & & \\
\hline Dialysis vintage & $6[3-10]$ & & \\
\hline \multicolumn{4}{|l|}{$\begin{array}{l}\text { Etiology of renal } \\
\text { failure }(\%)\end{array}$} \\
\hline $\begin{array}{l}\text { Diabetic nephropa- } \\
\text { thy }\end{array}$ & 38 & & \\
\hline $\begin{array}{l}\text { Chronic glomerular } \\
\text { nephritis }\end{array}$ & 18 & & \\
\hline Nephrosclerosis & 14 & & \\
\hline
\end{tabular}

The original article can be found online at https://doi.org/10.1007/ s10157-019-01715-8.

Hirokazu Okada

hirookda@saitama-med.ac.jp

1 Department of Nephrology, Faculty of Medicine, Saitama Medical University, 38, Morohongo, Moroyama-machi, Irumagun, Saitama, Japan

2 Community Health Science Center, Saitama Medical University, 38, Morohongo, Moroyama-machi, Irumagun, Saitama, Japan

3 Hemodialysis Unit, Saitama Medical University, 38, Morohongo, Moroyama-machi, Irumagun, Saitama, Japan

\begin{tabular}{|c|c|c|c|}
\hline Characteristics & April & September & $p$ value \\
\hline $\begin{array}{l}\text { Polycystic kidney } \\
\text { disease }\end{array}$ & 5 & & \\
\hline $\begin{array}{l}\text { ANCA associated } \\
\text { vasculitis }\end{array}$ & 0.8 & & \\
\hline Others & 24 & & \\
\hline PTX history (\%) & 1 & & \\
\hline BMI $\left(\mathrm{kg} / \mathrm{m}^{2}\right)$ & $21.3[19.2-23.8]$ & $21.2[19.1-23.9]$ & $<0.001$ \\
\hline GNRI (\%) & $95[89-101]$ & $94[89-100]$ & 0.01 \\
\hline BUN (mg/dL) & $63 \pm 14$ & $59 \pm 14$ & $<0.001$ \\
\hline $\mathrm{Cr}(\mathrm{mg} / \mathrm{dL})$ & $10.5 \pm 2.7$ & $10.6 \pm 2.6$ & 0.2 \\
\hline Alb (g/dL) & $3.6[3.4-3.8]$ & $3.6[3.4-3.8]$ & 0.02 \\
\hline Corrected $\mathrm{Ca}(\mathrm{mg} / \mathrm{dL})$ & $9.1[8.7-9.6]$ & $9.2[8.8-9.6]$ & 0.01 \\
\hline $\begin{array}{l}\text { Serum phosphorus } \\
(\mathrm{mg} / \mathrm{dL})\end{array}$ & $5.4[4.7-6.2]$ & $5.2[4.5-6.0]$ & $<0.001$ \\
\hline I-PTH (pg/dL) & $147[83-213]$ & $127[76-210]$ & $<0.001$ \\
\hline $\mathrm{Hb}(\mathrm{g} / \mathrm{dL})$ & 10.8 [10.2-11.4] & $10.8[10.2-11.4]$ & 0.8 \\
\hline Ferritin $(\mathrm{ng} / \mathrm{mL})$ & 56 [24-134] & 64 [24-144] & 0.08 \\
\hline TSAT $(\%)$ & $26[18-40]$ & $27[19-43]$ & 0.04 \\
\hline $\mathrm{Kt} / \mathrm{V}$ & $1.4[1.3-1.6]$ & $1.5[1.3-1.6]$ & $<0.001$ \\
\hline
\end{tabular}

Unless otherwise indicated, the values for continuous variables are presented as mean \pm standard deviation or median (interquartile range). We choose an appropriate test, either the paired $t$ test or Wilcoxon signed- rank test, as per the distribution of the variable ANCA antineutrophil cytoplasmic antibody, PTX parathyroidectomy, $B M I$ body mass index, GNRI geriatric nutritional risk index, $B U N$ blood urea nitrogen, $\mathrm{Cr}$ serum creatinine, $\mathrm{Alb}$ serum albumin, $I-P T H$ intact parathyroid hormone, Corrected $\mathrm{Ca}$ corrected serum calcium, TSAT transferrin saturation, $H b$ hemoglobin 